\title{
ON INFLUENCE OF CONCENTRACED MASS ON INSTABILITY AND VIBRATION OF A COLUMN SUBJECTED TO EULER'S LOAD
}

\author{
Krzysztof Sokót \\ Institute of Mechanics and Machine Design Foundation, Czestochowa University \\ of Technology, Poland \\ sokol@imipkm.pcz.pl
}

\begin{abstract}
In this paper, the results of numerical studies on vibration and instability of a geometrically nonlinear column subjected to Euler's load are presented. The system is loaded by external axial force $P$ applied at the free end of the column. Additional concentrated mass is localised on one of column's rods. The Hamilton principle was used to formulate the boundary problem. Due to the geometrical nonlinearity, the solution of the problem was performed by means of the small parameter method. The main purpose of this paper is to investigate an influence of the concentrated mass on divergence instability and critical loading and natural vibration frequency.
\end{abstract}

\section{Introduction}

The study on natural vibration and divergence instability of the geometrically nonlinear slender systems subjected to Euler's loading were the subject of numerous scientific investigations. The following parameters were mainly investigated: bending rigidity coefficient, stiffness of supporting and/or connecting springs, size of cracks, types of instability and magnitude of critical loading.

In this study the problem of natural vibration of the geometrically nonlinear column consisted of four rods with divergence instability is taken into account. Przybylski [1] and Tomski [2] have studied divergence instability of numerous systems subjected to Euler's loading. In the investigated system the first and the second element have a rigid connection. In the point of this connection concentrated mass has been placed. Uzny and Tomski [3-5] have studied nonlinear slender systems with concentrated mass. The main purpose of their work was to investigate natural vibration frequency, instability and critical loading. Rods three and four are connected by a pin, strengthened by a rotational spring with stiffness $C$. This type of connection allows one to simulate internal cracks and/or connection of elements made of different materials. The scientific research of columns with crack were investigate by Kukla [6] and Wang [7]. The problem of instability and natural vibration has been formulated by means of Hamilton's principle [8]. Solu- 
tion of investigated problem has been performed by use of small parameter method [9]. The main purpose of this investigation is to estimate an influence of concentrated mass on natural vibration frequency and critical loading.

\section{Formulation of the problem}

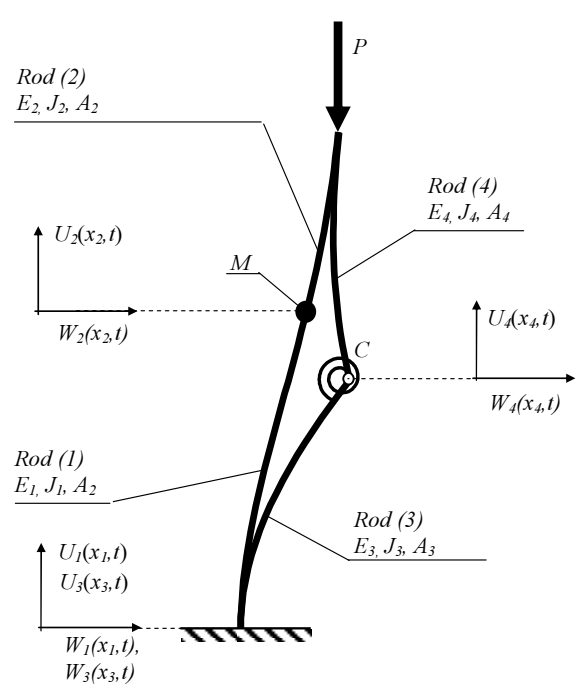

Fig. 1. The nonlinear system under consideration subjected to generalized load a)

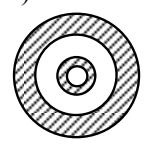

b)

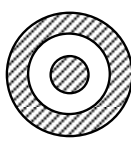

c)
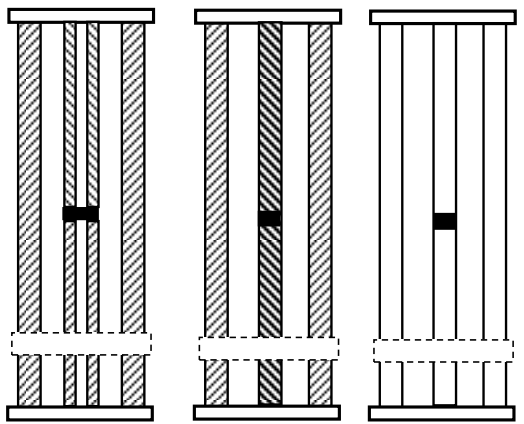

Fig. 2. Exemplary models of real life structures

Figure 1 presents an investigated nonlinear cantilever column. The first and the second rod have a rigid connection. In the point of this connection concentrated mass has been placed. Rods three and four are connected by a pin, strengthened by a rotational spring with stiffness $C$. This type of connection allows one to simulate internal cracks and/or connection of elements made of different materials. Method of formulation of the problem presented in this paper allows one also to simulate the change in location of the mass and of the spring along the column length. The column is loaded by external force $P$ in the point of connection of rods two and four. The deflection angles of these rods are identical. Examples of physical structures are presented in Figure 2 (a) two coaxial tubes, b) tube and rod, c) flat frame) where the black rectangular stands for the place where the spring $C$ is installed.

The problem presented in this paper has been formulated by means of Hamilton's principle:

$$
\delta \int_{t_{1}}^{t_{2}}(T-V) d t=0
$$


where the kinetic $T$ and potential $V$ energy are expressed by the following formulas:

$$
\begin{aligned}
& T=\frac{1}{2} \sum_{i=1}^{4} \int_{0}^{l_{i}} \rho_{i} A_{i}\left(\frac{\partial W_{i}\left(x_{i}, t\right)}{\partial t}\right)^{2} d x_{i}+\frac{1}{2} M\left(\frac{\partial W_{1}\left(x_{1}, t\right)}{\partial t}\right)_{x_{1}=l_{1}}^{2}+ \\
& +J m\left(\frac{\partial^{2} W_{1}\left(x_{1}, t\right)}{\partial x \partial t}\right)_{x_{1}=l_{1}}^{2} \\
& V=\frac{1}{2}\left\{\sum_{i=1}^{4} \int_{0}^{l_{i}} E_{i} J_{i}\left[\frac{\partial^{2} W_{i}\left(x_{i}, t\right)}{\partial x_{i}^{2}}\right]^{2} d x_{i}+\int_{0}^{l_{i}} E_{i} A_{i}\left[\frac{\partial U_{i}\left(x_{i}, t\right)}{\partial x_{i}}+\frac{1}{2}\left(\frac{\partial W_{i}\left(x_{i}, t\right)}{\partial x_{i}}\right)^{2}\right]^{2} d x_{i}\right\}+ \\
& +\frac{1}{2} C\left(\left.\frac{\partial W_{4}\left(x_{4}, t\right)}{\partial x_{4}}\right|_{x_{4}=0}-\left.\frac{\partial W_{3}\left(x_{3}, t\right)}{\partial x_{3}}\right|_{x_{3}=l_{3}}\right)^{2}+P U_{2}\left(l_{2}, t\right)
\end{aligned}
$$

Introducing the kinetic (2) and potential (3) energy into (1) and performing the variational and integration operations, and assuming that virtual longitudinal $\delta U_{i}\left(x_{i}, t\right)$ and transversal $\delta W_{i}\left(x_{i}, t\right)$ displacements for $i=1,2,3,4$ are arbitrary and independent for $0<x_{i}<l_{i}$ the following equations of motion in transversal direction were obtained:

$$
\begin{gathered}
E_{i} J_{i} \frac{\partial^{4} W_{i}\left(x_{i}, t\right)}{\partial x_{i}^{4}}-E_{i} A_{i} \frac{\partial}{\partial x_{i}}\left[\left[\frac{\partial U_{i}\left(x_{i}, t\right)}{\partial x_{i}}+\frac{1}{2}\left(\frac{\partial W_{i}\left(x_{i}, t\right)}{\partial x_{i}}\right)^{2}\right] \frac{\partial W_{i}\left(x_{i}, t\right)}{\partial x_{i}}\right]+\rho_{i} A_{i} \frac{\partial^{2} W_{i}\left(x_{i}, t\right)}{\partial t^{2}}=0 \\
i=1,2,3,4
\end{gathered}
$$

The compressive axial force is defined as follows:

$$
S_{i}(t)=-E_{i} A_{i}\left(\frac{\partial U_{i}\left(x_{i}, t\right)}{\partial x_{i}}+\frac{1}{2}\left[\frac{\partial W_{i}\left(x_{i}, t\right)}{\partial x_{i}}\right]^{2}\right) \quad i=1,2,3,4
$$

Introducing definition of axial force (5) into equation of motion, equation (4) has the form:

$$
E_{i} J_{i} \frac{\partial^{4} W_{i}\left(x_{i}, t\right)}{\partial x_{i}^{4}}+S_{i}(t) \frac{\partial^{2} W_{i}\left(x_{i}, t\right)}{\partial x_{i}^{2}}+\rho_{i} A_{i} \frac{\partial^{2} W_{i}\left(x_{i}, t\right)}{\partial t^{2}}=0 \quad i=1,2,3,4
$$


The axial displacement in each rod is expressed by the formula:

$$
U_{i}\left(x_{i}, t\right)=-\frac{S_{i}(t) x_{i}}{E_{i} A_{i}}-\frac{1}{2} \int_{0}^{x_{i}}\left[\frac{\partial W_{i}\left(x_{i}, t\right)}{\partial x_{i}}\right]^{2} d x_{i} \quad i=1,2,3,4
$$

The geometrical boundary conditions are as follows:

$$
\begin{array}{ll}
\left.W_{1}\left(x_{1}, t\right)\right|_{x_{1}=0}=\left.W_{1}^{I}\left(x_{1}, t\right)\right|_{x_{1}=0}=0 & \left.W_{3}\left(x_{3}, t\right)\right|_{x_{3}=0}=\left.W_{3}^{I}\left(x_{3}, t\right)\right|_{x_{3}=0}=0 \\
\left.W_{2}^{I}\left(x_{2}, t\right)\right|_{x_{2}=l_{2}}=\left.W_{4}^{I}\left(x_{4}, t\right)\right|_{x_{4}=l_{4}} & \left.W_{3}\left(x_{3}, t\right)\right|_{x_{3}=l_{3}}=\left.W_{4}\left(x_{4}, t\right)\right|_{x_{4}=0} \\
\left.W_{1}\left(x_{1}, t\right)\right|_{x_{1}=l_{1}}=\left.W_{2}\left(x_{2}, t\right)\right|_{x_{2}=0} & \left.W_{2}\left(x_{2}, t\right)\right|_{x_{2}=l_{2}}=\left.W_{4}\left(x_{4}, t\right)\right|_{x_{4}=l_{4}} \\
U_{1}(0, t)=U_{3}(0, t)=0 & U_{2}(0, t)=U_{1}\left(l_{1}, t\right) \\
U_{2}\left(l_{2}, t\right)=U_{4}\left(l_{4}, t\right) & U_{4}(0, t)=U_{3}\left(l_{3}, t\right)
\end{array}
$$

$(8 \mathrm{a}-\mathrm{m})$

By introducing $(8 \mathrm{a}-\mathrm{m})$ to the variational equation, the following set of natural boundary conditions can be obtained:

$$
\begin{gathered}
\left.E_{2} J_{2} W_{2}^{I I}\left(x_{2}, t\right)\right|_{x_{2}=l_{2}}+\left.E_{4} J_{4} W_{4}^{I I}\left(x_{4}, t\right)\right|_{x_{4}=l_{4}}=0 \\
\left.E_{2} J_{2} W_{2}^{I I I}\left(x_{2}, t\right)\right|_{x_{2}=l_{2}}+\left.P W_{2}^{I}\left(x_{2}, t\right)\right|_{x_{2}=l_{2}}+\left.E_{4} J_{4} W_{4}^{I I I}\left(x_{4}, t\right)\right|_{x_{4}=l_{4}}=0 \\
\left.E_{3} J_{3} W_{3}^{I I I}\left(x_{3}, t\right)\right|_{x_{3}=l_{3}}+\left.S_{3} W_{3}^{I}\left(x_{3}, t\right)\right|_{x_{3}=l_{3}}+ \\
-\left.E_{4} J_{4} W_{4}^{I I I}\left(x_{4}, t\right)\right|_{x_{4}=0}-\left.S_{4} W_{4}^{I}\left(x_{4}, t\right)\right|_{x_{4}=0}=0 \\
-\left.E_{4} J_{4} W_{4}^{I I}\left(x_{4}, t\right)\right|_{x_{4}=0}+C\left[\left.W_{4}^{I}\left(x_{4}, t\right)\right|_{x_{4}=0}-\left.W_{3}^{I}\left(x_{3}, t\right)\right|_{x_{3}=l_{3}}\right]=0 \\
\left.E_{1} J_{1} W_{1}^{I I I}\left(x_{1}, t\right)\right|_{x_{1}=l_{1}}+\left.S_{1} W_{1}^{I}\left(x_{1}, t\right)\right|_{x_{1}=l_{1}}-\left.E_{2} J_{2} W_{2}^{I I I}\left(x_{2}, t\right)\right|_{x_{2}=0}-\left.S_{2} W_{2}^{I}\left(x_{2}, t\right)\right|_{x_{2}=0}+ \\
-\left.m \ddot{W}_{1}\left(x_{1}, t\right)\right|_{x_{1}=l_{1}}=0 \\
\left.E_{1} J_{1} W_{1}^{I I}\left(x_{1}, t\right)\right|_{x_{1}=l_{1}}-\left.E_{2} J_{2} W_{2}^{I I}\left(x_{2}, t\right)\right|_{x_{2}=0}+J m \frac{\partial^{3} W_{1}\left(l_{1}, t\right)}{\partial x \partial t^{2}}=0 \\
\left.E_{3} J_{3} W_{3}^{I I}\left(x_{3}, t\right)\right|_{x_{3}=l_{3}}-C\left[\left.W_{4}^{I}\left(x_{4}, t\right)\right|_{x_{4}=0}-\left.W_{3}^{I}\left(x_{3}, t\right)\right|_{x_{3}=l_{3}}\right]=0 \\
S_{1}=S_{2} \quad P=S_{1}+S_{3}
\end{gathered}
$$

In the boundary conditions the roman numerals determines the derivatives with respect to space variable $x_{i}$ and the dots the derivatives with respect to time $t$.

The small parameter $\varepsilon$ method [9] has been used to solve the boundary problem due to geometrical nonlinearities of the column. According to this method for the 
system vibrating around the rectilinear form of static equilibrium the longitudinal and transversal displacements, axial force and vibration frequency of each rod are written in a power series

$$
\begin{array}{ll}
w_{i}(\xi, \tau)=\sum_{n=1}^{N} \varepsilon^{2 n-1} w_{i 2 n-1}(\xi, \tau)+O\left(\varepsilon^{2 N+1}\right) & u_{i}(\xi, \tau)=u_{i 0}(\xi)+\sum_{n=1}^{N} \varepsilon^{2 n} u_{i 2 n}(\xi, \tau)+O\left(\varepsilon^{2 N+1}\right) \\
k_{i}(\tau)=k_{i o}+\sum_{n=1}^{N} \varepsilon^{2 n} k_{i 2 n}(\tau)+O\left(\varepsilon^{2 N+1}\right) & \omega_{i}^{2}=\omega_{0 i}{ }^{2}+\sum_{n=1}^{N} \varepsilon^{2 n} \omega_{i 2 n}{ }^{2}+O\left(\varepsilon^{2 N+1}\right)(10 \mathrm{a}-\mathrm{d})
\end{array}
$$

Then, the obtained terms are grouped at the same power of the small parameter $\varepsilon$, which leads to infinite sequence of equations. The solution presented in this paper was obtained on the basis of a system of equations with a small parameter in the first power.

\section{Results of numerical calculations}

Results of numerical calculations of vibration frequency and instability are referred to the reference system. The reference system has no concentrated mass and is composed of rods with identical bending rigidity factor $\left(r_{\mathrm{m}}=r_{\mathrm{w}}=1\right)$.

In Figures 3 and 4 curves of non-dimensional relation external load $p$ vs. vibration frequency $\omega$ for different spring stiffness $c$ are presented. Smaller values of $c$ results in smaller magnitudes of vibration frequency and critical loading of a column. For greater $c$ vibration frequency and critical loading are rising up to $p_{c r}=2.4649$. It can be concluded that vibration frequency and critical loading of a referenced system is highly dependant on spring stiffness. Shape modes of a referenced system for different spring stiffness are presented in the appendix.

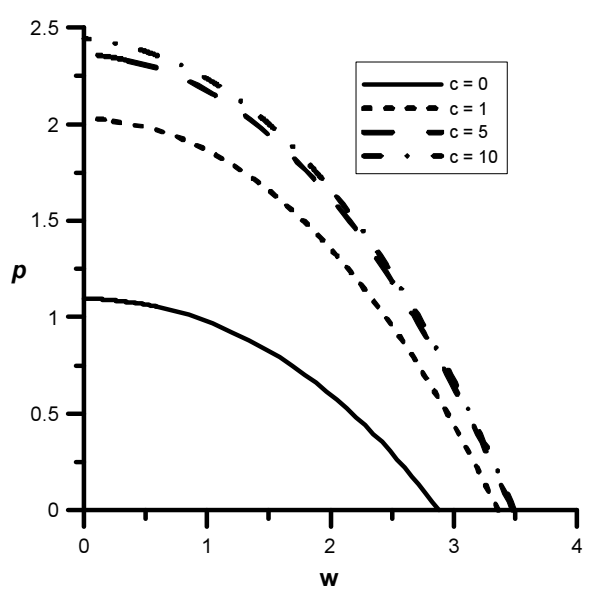

Fig. 3. Curves external load vs. vibration frequency for different spring stiffness $\left(d_{2}=0.5\right.$, $d_{3}=0.5, r_{m}=1, r_{w}=1, m=0$ )

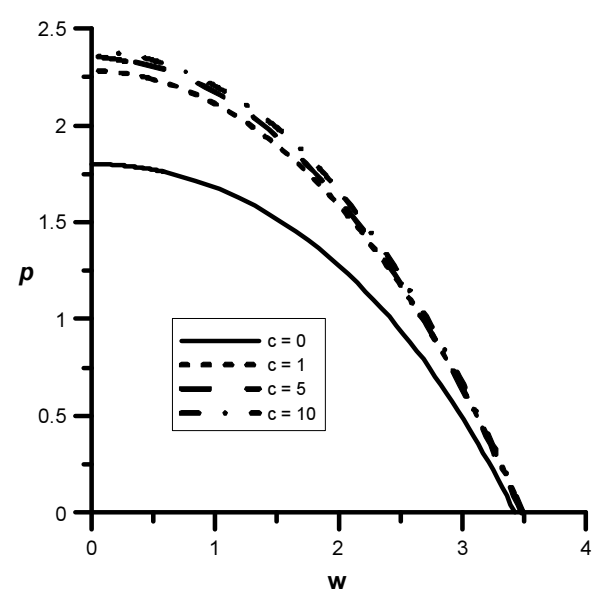

Fig. 4. Curves external load vs. vibration frequency for different spring stiffness $\left(d_{2}=0.5\right.$, $\left.d_{3}=0.7, r_{m}=1, r_{w}=1, m=0\right)$ 
In Figures 5-8 an influence of the concentrated mass $m$ for two different spring stiffnesses $c=1,10$ and it's location $d_{3}=0.5$ and 0.7 is presented.

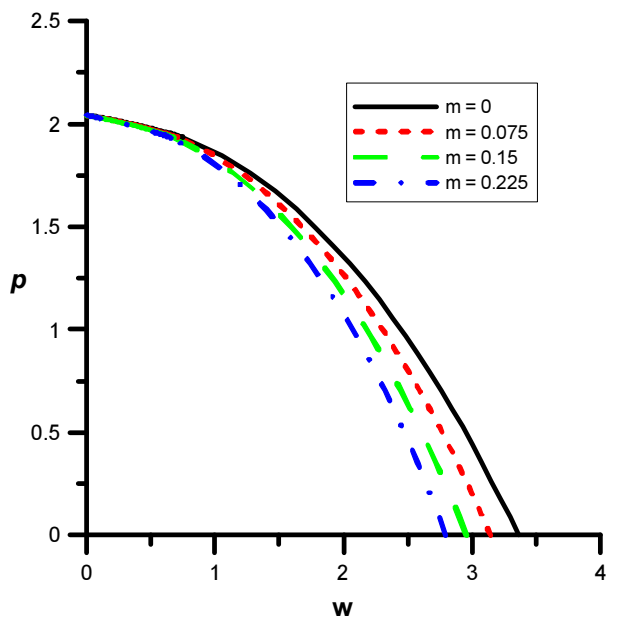

Fig. 5. Curves external load vs. vibration frequency for different mass magnitude $\left(d_{2}=0.5, d_{3}=0.5, r_{m}=1, r_{w}=1, c=1\right)$

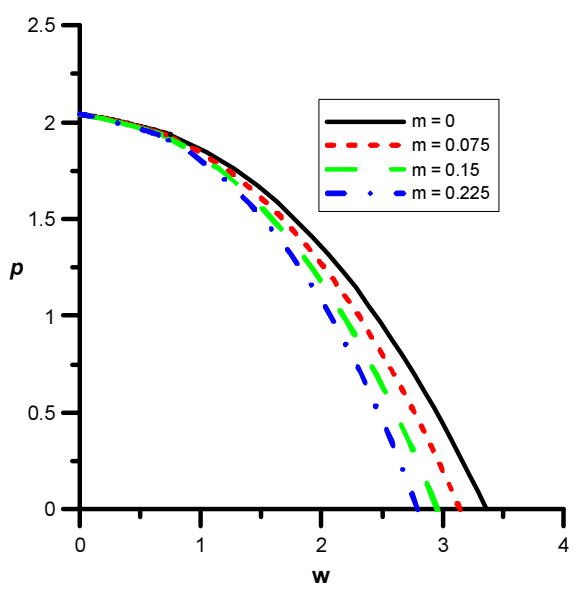

Fig. 7. Curves external load vs. vibration frequency for different mass magnitude $\left(d_{2}=0.5, d_{3}=0.7, r_{m}=1, r_{w}=1, c=1\right)$

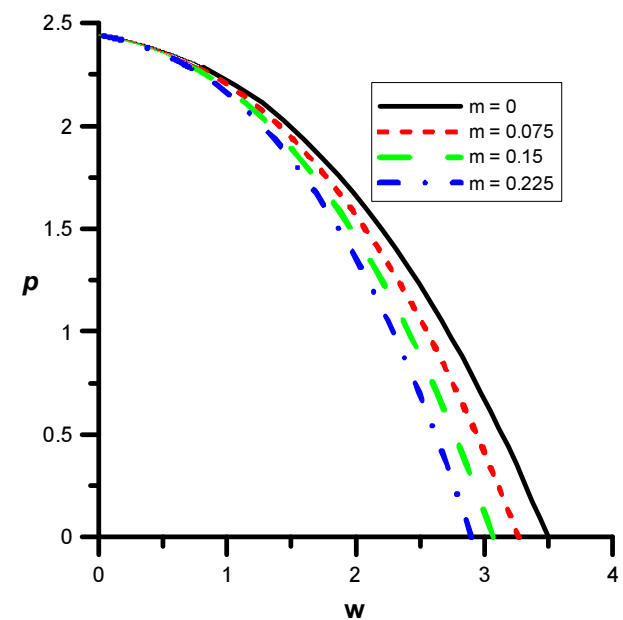

Fig. 6. Curves external load vs. vibration frequency for different mass magnitude $\left(d_{2}=0.5, d_{3}=0.5, r_{m}=1, r_{w}=1, c=10\right)$

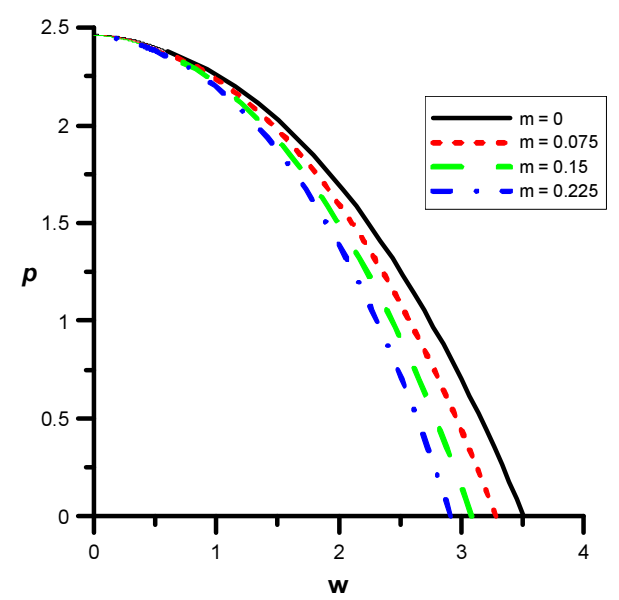

Fig. 8. Curves external load vs. vibration frequency for different mass magnitude $\left(d_{2}=0.5, d_{3}=0.7, r_{m}=1, r_{w}=1, c=10\right)$

When the pin is localized in the middle of the total length of the investigated column two different spring stiffnesses $c=1$ and $c=10$ are chosen to be presented in the Figures 5 and 6 respectively. Continuous curve refers to the column without mass $m$. For this configuration the vibration frequency magnitude is the highest. 
The increase of magnitude of mass $m$ results in the reduction of natural vibration frequency irrespective of spring stiffness. Despite the magnitude of mass $m$ the critical loading of a column is constant for chosen configuration of the system. When the mass $m=0$ vibration frequency $\omega=3.361$ and for $m=0.225$ vibration frequency $\omega=2.796$ (data from Figure 5).

Figures 7 and 8 refer to the configuration in which the pin and the spring are localised in position described by $d_{3}$ parameter $\left(d_{3}=0.7\right)$. An influence of the mass $m$ on the investigated factors is exactly the same as in the previous figures (Fig. 5 and 6). It can be concluded that the mass $m$ allows one to control vibration frequency and has no influence on the critical loading.

Since mass $m$ has no influence on critical loading the following picture has been created (Fig. 9). This figure presents critical loading vs. pin location curves which are plotted for different spring stiffness.

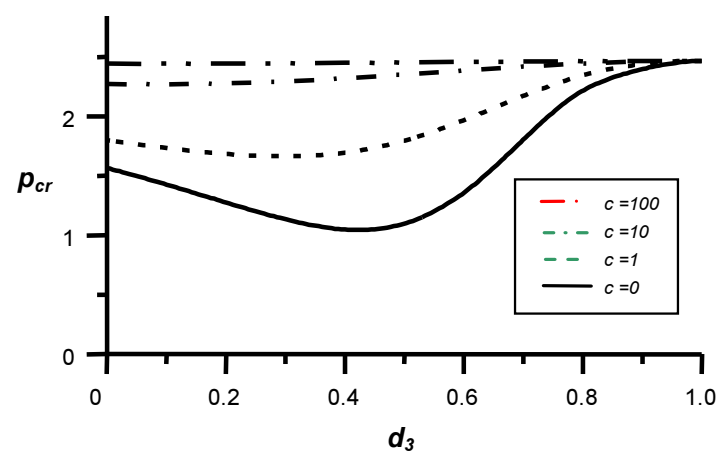

Fig. 9. Influence of the pin location on critical load $\left(d_{2}=0.5, d_{3}=0.5, r_{m}=1, r_{w}=1, m=0\right)$

If spring stiffens tends to infinity the critical loading is constant and change in $d_{3}$ parameter has no influence on investigated factor. Reduction of spring stiffness results in a decrease in critical loading. The smaller $c$ the greater change in critical loading. Despite the changes in spring stiffness, the magnitude of the critical loading is stabilizing with the approach to the free end by the pin.

\section{Conclusions}

In this paper an influence of concentrated mass along the column length on divergence instability and natural vibration of the geometrically nonlinear column subjected to Euler's load is presented. The following conclusions have been made after analysis of the results of numerical calculations:

- the magnitude of the mass $m$ has a great influence on the shape of curves drawn in the force - vibration frequency plane,

- the greater the mass the lower natural vibration frequency, 
- the magnitude of the mass $m$ has no influence on vibration modes and what in important on critical loading of the column,

- by means of the additional mass $m$ the natural vibration frequency and the operating range of the column can be controlled,

- for $c<5$ the localization of the pin has a great influence on critical loading and natural vibration frequency. By the change of the localization of the pin the critical load can be controlled,

- when the pin is localized near the loaded end of the column the influence of the spring stiffness on investigated parameters is negligible.

\section{References}

[1] Przybylski J., Drgania i stateczność dwuczłonowych układów prętowych wstępnie sprężonych przy obciążeniach niezachowawczych, Częstochowa 2002 (in Polish).

[2] Tomski L., Szmidla J., Uzny S., The local and global instability and vibration of the system subjected to non-conservative loading, Thin Walled Structures 2007, 45, 945-949.

[3] Tomski L., Uzny S., Vibration and stability of geometrically nonlinear column subjected to generalized load with a force directed toward the positive pole, International Journal of Structural Stability and Dynamisc 2008, 8, 1, 1-23.

[4] Tomski L., Uzny S., Free vibrations and stability of a geometrically nonlinear column loaded by a fllower force directed towards the positive pole, International Journal of Solids and Structures 2008, 45, 87-112.

[5] Uzny S., An elastically supported geometrically nonlinear slender system subjected to a specific load in respect of bifurcation load and free vibrations, International Journal of Bifurcation and Chaos 2011, 21, 10, 2983-2992.

[6] Kukla S., Free vibration and stability of stepped columns with cracks, Journal of Sound and Vibration 2009, 319, 3-5, 1301-1311.

[7] Wang C.Y., Buckling of an internally hinged column with an elastic support, Engineering Structures 2002, 24, 357-1360.

[8] Skalmierski B., Mechanika, PWN, Warszawa 1982, 283-285 (in Polish).

[9] Osiński Z., Teoria drgań, PWN, Warszawa 1978, 52-54 (in Polish).

\section{Nomenclature}

$\begin{array}{llll}A_{i} & \text { Cross section area } & r_{\mathrm{m}} & \text { Bending stiffness ratio } E_{l} J_{l} / E_{2} J_{2} \\ E_{i} & \text { Young's modulus } & r_{\mathrm{w}} & \text { Bending stiffness ratio } E_{3} J_{3} / E_{4} J_{4} \\ J_{i} & \text { Area moment of inertia } & k_{i} & \text { Non-dimensional axial force } S_{i} l^{2} / E_{i} J_{i} \\ J_{m} & \text { Mass moment of inertia } & m & \text { Non-dimensional mass } \mathrm{M} / \rho A l \\ P & \text { External force } & w_{i} & \text { Non-dimensional transversal displacement } W_{i} / l \\ C & \text { Rotational spring stiffness } & u_{i} & \text { Non-dimensional axial displacement } U_{i} / l \\ U_{i} & \text { Axial displacement } & d_{i} & \text { Non-dimensional length of a rod } l_{i} / l \\ W_{i} & \text { Transversal displacement } & \xi_{i,} \tau & \text { Non-dimensional space and time variable, respectively } \\ M & \text { Concentrated mass } & c & \text { Non-dimensional spring stiffness } C l /\left(E_{3} J_{3}+E_{4} J_{4}\right) \\ \rho_{i} & \text { Density of a material } & \omega_{i}{ }^{2} & \text { Non-dimensional natural frequency } \Omega^{2}\left(\rho_{i} A_{i} l^{4} / E_{i} J_{i}\right) \\ \Omega_{i} & \text { Natural vibration frequency } & p & \text { Non-dimensional external load } P l^{2} /\left(E_{l} J_{l}+E_{2} J_{2}\right)\end{array}$




\section{Appendix}

Table 1. Shape modes $\left(d_{2}=0.5, d_{3}=0.5, r_{m}=1, r_{w}=1, m=0\right)$

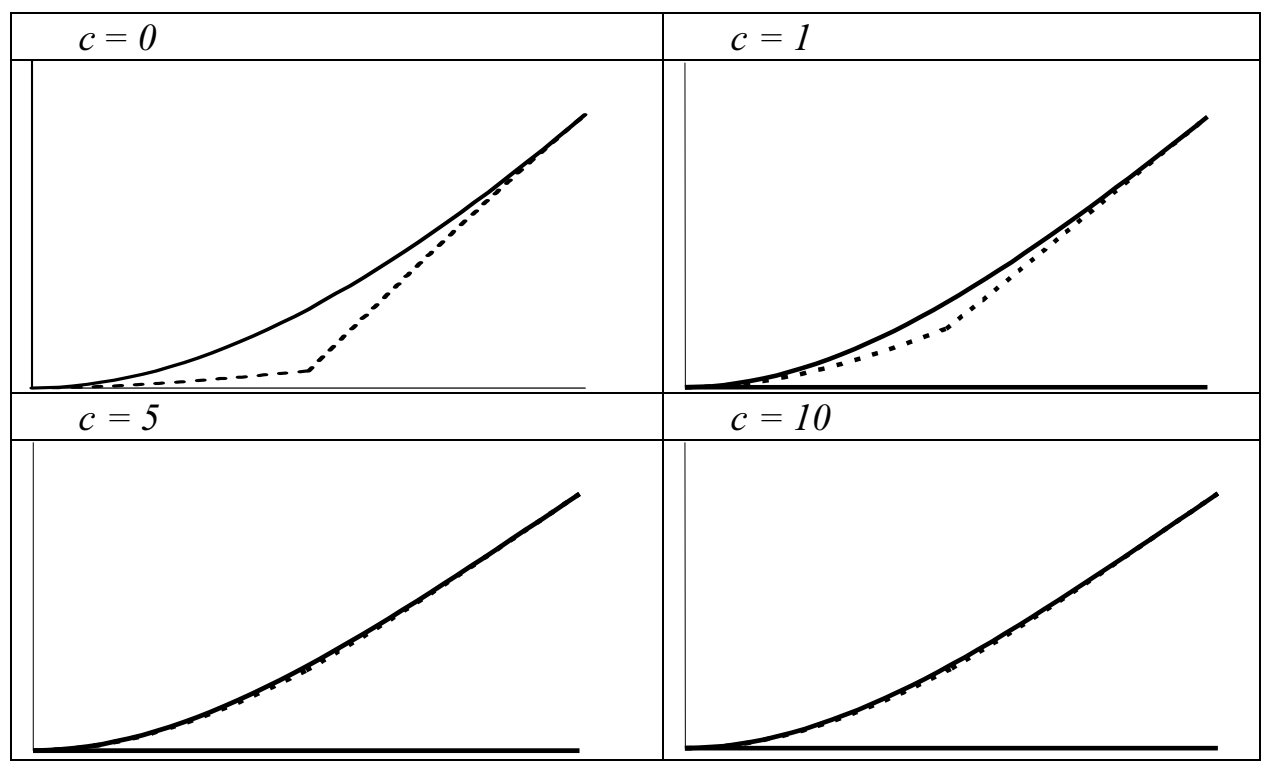

Table 2. Shape modes $\left(d_{2}=0.5, d_{3}=0.7, r_{m}=1, r_{w}=1, m=0\right)$

\begin{tabular}{|l|l|}
\hline$c=0$ & $c=1$ \\
\hline &
\end{tabular}

